\title{
A Study on the Synthesis and Anticancer Activities of Novel 6-Methoxy Flavonyl Piperazine Derivatives ${ }^{\dagger}$
}

\author{
Meltem Ceylan-Ünlüsoy * and Oya Bozdağ-Dündar \\ Department of Pharmaceutical Chemistry, Faculty of Pharmacy, Ankara University, Ankara 06100, Turkey; \\ bozdag@pharmacy.ankara.edu.tr \\ * Correspondence: munlusoy@pharmacy.ankara.edu.tr; Tel.: +90-312-203-3079 \\ + Presented at the 2nd International Conference on Natural Products for Cancer Prevention and Therapy, \\ Kayseri, Turkey, 8-11 November 2017.
}

Published: 17 November 2017

\begin{abstract}
Cancer is an extensive and complicated family of malignancies that can affect virtually every part of the body. It is reported that over 1.2 million new cases are diagnosed every year. In most of the patients, meaningful clinical results cannot be achieved by the currently available cancer therapies and we still need efficient probes as drugs to cure. Natural products have long been a source of antitumor drugs and new natural products are reasonable to be expected as promising leads for antitumor drug discovery. Among natural products, flavonoids are a group of polyphenolic compounds present in plants and they have attracted considerable attention by virtue of their diverse and interesting biological activities such as anti-inflammatory, neuroprotection and antitumor activity. In this study, we describe the synthesis of a new series of N-substituted 6methoxyflavonyl piperazine derivatives (Formula) with the aim of testing their cytotoxic and anticancer activities. The structural evaluation of the synthesized compounds was based on the ${ }^{1} \mathrm{H}$ NMR, Mass and elementary analysis data. The synthesized compounds are under investigation for their anticancer activities.
\end{abstract}

Keywords: flavones; anticancer activity; piperazine<smiles>[R]N1CCN(Cc2cccc(-c3cc(=O)c4cc(OC)ccc4o3)c2)CC1</smiles>

N-substituted 6-methoxyflavonyl piperazine derivatives.

Conflicts of Interest: The authors declare no conflict of interest.

(C) 2017 by the authors. Licensee MDPI, Basel, Switzerland. This article is an open access article distributed under the terms and conditions of the Creative Commons Attribution (CC BY) license (http://creativecommons.org/licenses/by/4.0/). 